\title{
DCM Frequency Control Algorithm for Multi-Phase DC-DC Boost Converters for Input Current Ripple Reduction
}

\author{
Dong-Myoung Joo*, Dong-Hee Kim* and Byoung-Kuk Lee ${ }^{\dagger}$
}

\begin{abstract}
In this paper, a discontinuous conduction mode (DCM) frequency control algorithm is proposed to reduce the input current ripple of a multi-phase interleaved boost converter. Unlike conventional variable duty and constant frequency control, the proposed algorithm controls the switching frequency to regulate the output voltage. By fixing the duty ratio at $1 / \mathrm{N}$ in the $\mathrm{N}$-phase interleaved boost converter, the input current ripple can be minimized by ripple cancellation. Furthermore, the negative effects of the diode reverse recovery current are eliminated because of the DCM characteristic. A frequency controller is designed to employ the proposed algorithm considering the magnetic permeability change. The proposed algorithm is analyzed in the frequency domain and verified by a $600 \mathrm{~W}$ three-phase boost converter prototype that achieved $57 \%$ ripple current reduction.
\end{abstract}

Keywords: Interleaved boost converter, Input current ripple reduction, DCM operation and fixed duty - frequency control

\section{Introduction}

Compared to the other types of renewable energy, fuel cells and photovoltaic generation systems are more suitable for distributed generation systems because of their several advantages such as lower environmental constraints and easy downsizing [1-3]. From the viewpoint of the load dependent voltage and slow dynamic characteristic of renewable energy, the power conditioning systems consist of converters and inverters to generate a stable output and for the proper output voltage level, boost converters are generally used for dc-dc converters.

A large input current ripple of the pulse width modulation (PWM) dc-dc converter is one of the obstacles to meet electromagnetic interference (EMI) requirements. Therefore, it is necessary to limit the input current ripple through proper equipment or a control method [4-8]. An additional hardware filter can be installed to limit the highfrequency input current ripple on the basis of the switching frequency. However, it has some drawbacks, such as power losses, cost, volume, and weight increase.

Several topologies without a filter have been proposed to reduce the input current ripple [4-8]. Reference [5] proposes double-Cúk with a coupled inductor, and it achieves a near-zero input current ripple. However, its double-stage configuration and the added passive components may decrease its efficiency and power density. The studies in [6-8] employ capacitors and inductors for ripple cancellation, and thus, these topologies also need additional components. Moreover, the operation mode of [7-8] is continuous

$\dagger$ Corresponding Author: Department of Electrical and Computer Engineering, Sungkyunkwan University, Korea. (bkleeskku@skku.edu)

* Department of Electrical and Computer Engineering, Sungkyunkwan University, Korea. (silvernoid@skku.edu)

Received: April 22, 2015; Accepted: July 8, 2015 conduction mode (CCM), which results in switching noise with steep $d v / d t$ and $d i / d t$ due to the reverse recovery current of the diode [9].

The boost converter with CCM operation has the advantages of lower peak, ripple, and RMS inductor current. In general, the input current ripple is also lower than in the DCM operation. However, the problems posed by the reverse recovery current of the diode are critical. Fig. 1(a) shows that the voltage ringing and snappy spikes of the MOSFET which are synchronized at diode turn-off unlike in the DCM, as shown in Fig. 1(b). Fig. 2 shows how MOSFET voltage stress is affected by the reverse recovery current, which increases the MOSFET voltage rating and $R_{D S(o n)}[10]$. This voltage spike is generated by the parasitic source inductance $L_{s}$ and the high $d i / d t$ current is expressed as

$$
V_{L S}=L_{s} \frac{d i}{d t}
$$

Although a parasitic source inductance is small, it can

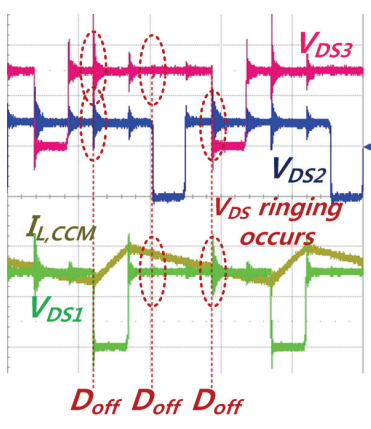

(a) CCM control

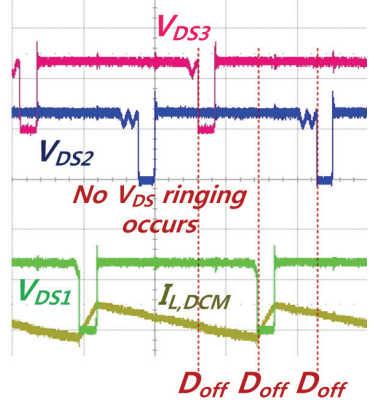

(b) DCM control
Fig. 1. Comparison of $V_{D S}$ for DCM and CCM control. 


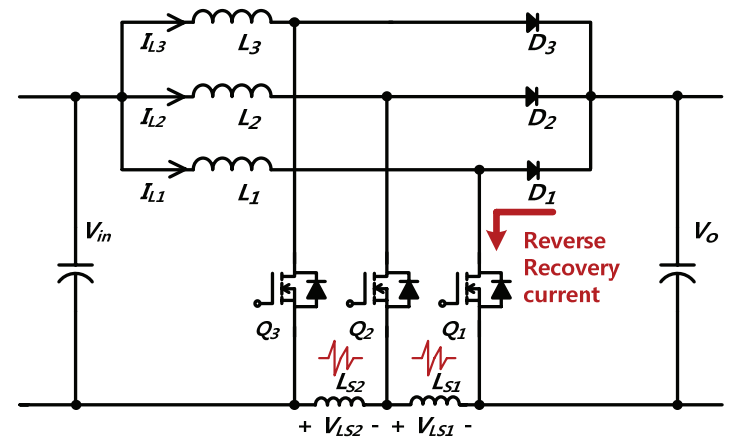

Fig. 2. Effect of reverse recovery current.

cause high-voltage ringing at the diode-off transition in the CCM owing to high $d i / d t[11]$.

The drawbacks of the CCM operation can be overcome by the DCM operation. The DCM multi-phase boost converter with interleaving control can be a strong candidate for reducing the input current ripple and eliminating the effects of the reverse recovery current [12-13]. However, the input current ripple is still higher than in the CCM operation under conventional variable duty and constant frequency control. Instead of duty control, the frequency would be controlled to regulate the output voltage in the DCM operation. Moreover, the input current ripple can be reduced at the optimum fixed duty by using frequency control.

In this paper, a fixed duty and variable frequency (FDVF) DCM control algorithm for the interleaved multiphase boost converter is proposed to reduce the input current ripple without using additional devices. Moreover, the negative effect of diode reverse recovery is solved by using the characteristics of DCM. Unlike the conventional DCM PWM duty control method, the duty ratio of the proposed control algorithm is fixed, and the frequency is changed to regulate the output voltage by using the voltage gain characteristic of DCM control. A $600 \mathrm{~W}$ prototype hardware is designed to verify the proposed frequency control algorithm. Compared to conventional PWM control, the input current ripple is reduced on average by $32 \%$, and its frequency varies from 11.3 to $37 \mathrm{kHz}$.

\section{Proposed Frequency Control Algorithm for Input Current Reduction}

\subsection{Optimum duty selection for input current ripple minimization}

The input current ripple of the CCM interleaved boost converter is shown in Fig. 3. The input current ripple is minimized by a duty of $360^{\circ} / N$ owing to the ripple cancellation effect. This means the input current ripple components are cancelled by the equal magnitudes of the rising and falling slopes. The duty ratio $D_{k}$ for minimizing the input current ripple can be expressed as follows:

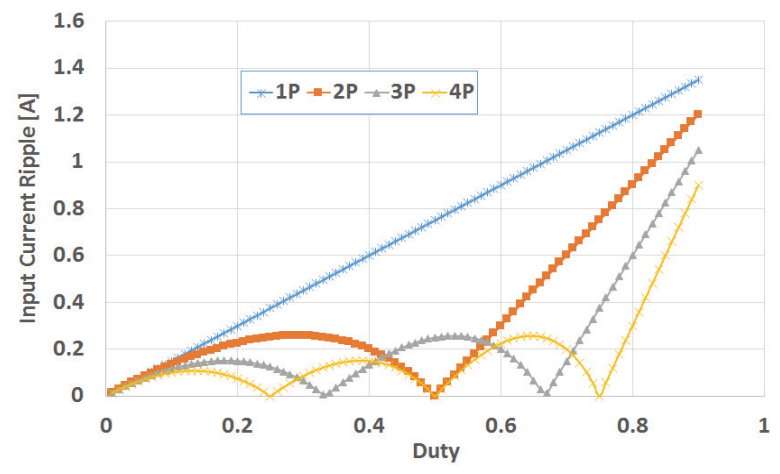

Fig. 3. Input current ripple comparison of the CCM.

$$
D_{k}=\frac{1}{N} \cdot k(k=1,2, \cdots N-1)
$$

Similarly, the input current ripple is minimized at the same duty in the DCM. However, the duty ratio of the $\mathrm{CCM}$ boost converter is

$$
G_{v, C C M}=\frac{V_{o}}{V_{\text {in }}}=\frac{1}{1-D} V_{\text {in }}
$$

where $V_{o}$ and $V_{\text {in }}$ are the output and input voltages, and $G_{v}$ is the voltage gain.

This means the output voltage is a function of the duty ratio, and it is determined by only the input and output voltages. Hence, in CCM, it is impossible for the operation of the optimum duty according to (2) for minimizing the input current ripple at all times. On the other hand, the voltage gain of the DCM boost converter is [14]

$$
G_{v, D C M}=\frac{1}{2}\left(1+\sqrt{1+\frac{2 D^{2} R_{o}}{L f_{s w}}}\right)
$$

where $R_{o}$ is the output resistance, $f_{s w}$ is the switching frequency, and $L$ is the boost inductance.

By controlling the switching frequency in the DCM operation instead of controlling the PWM duty ratio, the voltage gain of the boost converter can be regulated. Hence, the input current ripple current can be minimized by fixing the duty ratio at $1 / N$. Furthermore, the elimination of the negative effects of diode reverse recovery can be obtained.

\subsection{Duty determination for DCM operation}

The proposed frequency control is analyzed for the three-phase interleaved boost converter. The voltage gain of the boost converter in the DCM operation is given by (5). $D_{A}$ represents the proportion of the inductor current that falls to 0 in the switching period and is given by (6). The voltage gain $G_{v}$ of the DCM is always higher than that of the CCM because $D_{A}$ is smaller than 1 . 


$$
\begin{gathered}
G_{v}=\frac{V_{o}}{V_{\text {in }}}=\frac{D_{A}}{D_{A}-D} \geq \frac{1}{1-D} \\
D_{A}=\frac{T_{s w, \text { on })}+T_{D, \text { on })}}{T}, \quad 0<D_{A}<1
\end{gathered}
$$

where $T_{s w,(o n)}$ and $T_{D,(o n)}$ are the on times of the MOSFET and the diode, respectively.

Fig. 4 shows the voltage gain curve of the DCM and the CCM. The curve represents the voltage gain of the CCM, and the upper area of the curve is the available voltage gain of the DCM. When $D$ is $1 / 3$ or $2 / 3$, the voltage gain is $3 / 2$ or 3 . Thus, the minimum voltage gain of the proposed control is above $3 / 2$ in the three-phase case.

If a voltage gain over 3 is required, theoretically, duties of both $1 / 3$ and $2 / 3$ can be selected; however, the calculated switching frequency will be too low. Therefore, a duty of $2 / 3$ is suitable in this case. Similarly, the optimum duty for the voltage gain between $3 / 2$ and 3 is $1 / 3$. From (1), the expression for the general selection guide for the N-phase boost converter is given by (7). The visualized duty ratio selection guide of the proposed frequency for the threephase and N-phase boost converter is shown in Fig. 5.

$$
\begin{aligned}
& G_{v, k}=\frac{1}{1-D_{k}}=\frac{1}{1-\frac{k}{N}}=\frac{N}{N-k} \\
& D_{k} \text { for } G_{v, k} \leq G_{v, r e q} \leq G_{v, k+1}
\end{aligned}
$$

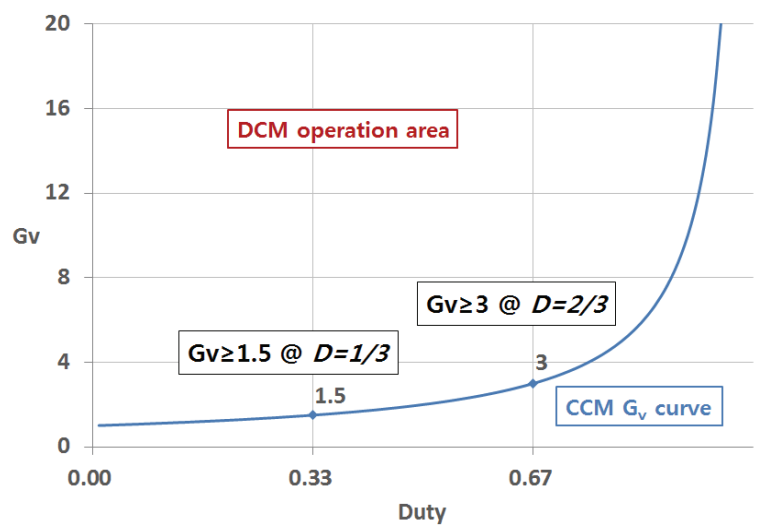

Fig. 4. DCM operation area and voltage gain.

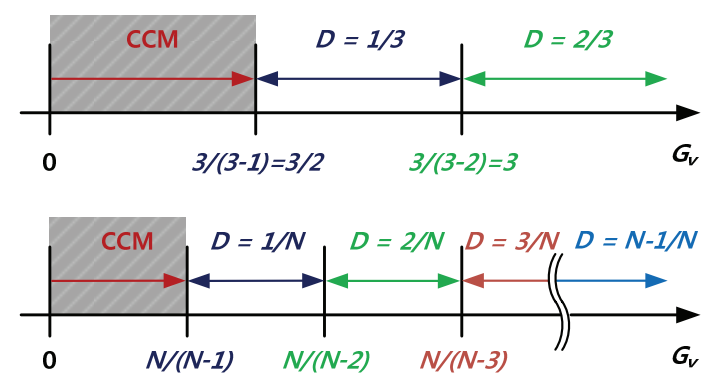

Fig. 5. Duty ratio according to voltage transfer ratio.

\subsection{Variable switching frequency control algorithm}

The switching frequency should be calculated to achieve the required step-up ratio after the duty ratio is determined. In terms of the switching frequency, rewriting (4) yields

$$
f_{s w}=\frac{2 D^{2} R_{o}}{\left\{\left(\frac{2 V_{o}}{V_{i n}}-1\right)^{2}-1\right\} L}
$$

Substituting $R_{o}$ from (9) by using Ohm's law:

$$
f_{s w}=\frac{2 D^{2} V_{o}}{\left\{\left(\frac{2 V_{o}}{V_{\text {in }}}-1\right)^{2}-1\right\} L I_{o}}
$$

where $I_{o}$ is the output current.

The duty ratio is predetermined in Section 2.2, and the inductance is a constant value according to the system design. The voltage gain expressed by (9) corresponds to an ideal case as the permeability variation of the inductor has been ignored. As shown in Fig. 6, in the practical design, the inductance will be changed by the amount of current applied. In order to quantify the roll-off, consider the variation in inductance as a function of the inductor current $i_{L}[15]$ :

$$
f_{s w}=\frac{2 D^{2} V_{o}}{\left\{\left(\frac{2 V_{o}}{V_{\text {in }}}-1\right)^{2}-1\right\} L_{\text {int }} f\left(I_{L}\right) I_{o}}
$$

where $L_{\text {int }}$ is the initial inductance at $I=0 \mathrm{~A}$.

The variation in the inductance increases the output voltage regulation error. Thus, the inductance roll-off should be compensated. One method to achieve this is to model the inductance as a function of $i_{L}$ into (10). However, this method cannot be applied for a common design owing to the need for inductor analysis and the nonlinear characteristics of permeability. The problem can be solved

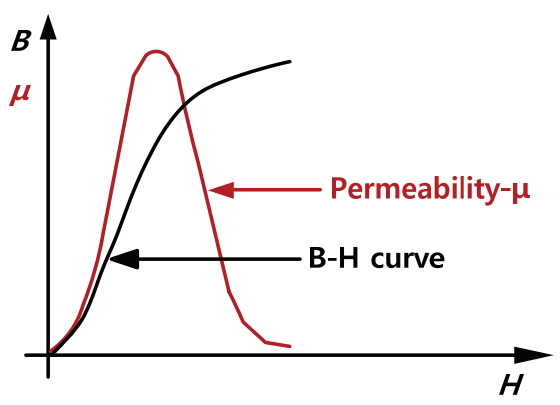

Fig. 6. B-H curve of magnetic components. 
by using the conventional PI controller in addition to the proposed frequency controller. In the inductor design process, the permeability decrease ratio of the inductance is limited to approximately $20 \%$. The maximum value of the duty ratio change is the reciprocal of the inductance change. Therefore, a PI controller can be applied to the proposed frequency algorithm without a significant duty change, and the output voltage can be regulated as follows voltage reference $V_{r e f}^{*}$.

\subsection{Controller modeling and design}

The stability of proposed control algorithm should be verified according to the frequency variation range due to variable frequency and fixed duty characteristic. The current control loop model for the three-phase boost converter system is shown in Fig. 7. The three-phase interleaved boost converter is controlled by the average current mode control to obtain a fast response for the load and input voltage changes by sensing the output voltage and the inductor current. The controller design targets the lowest input voltage because from (10), the switching frequency is proportional to the input voltage.

The designed frequency controller is shown in Fig. 8. The operating duty is selected from the ratio of $V_{o}$ and the output voltage reference $V_{r e f}^{*}$, and the frequency is determined from the designed inductance value and the sensed output current and voltage for real implementation. The frequency limiter limits too low or high switching frequencies to prevent saturation of the inductor core and

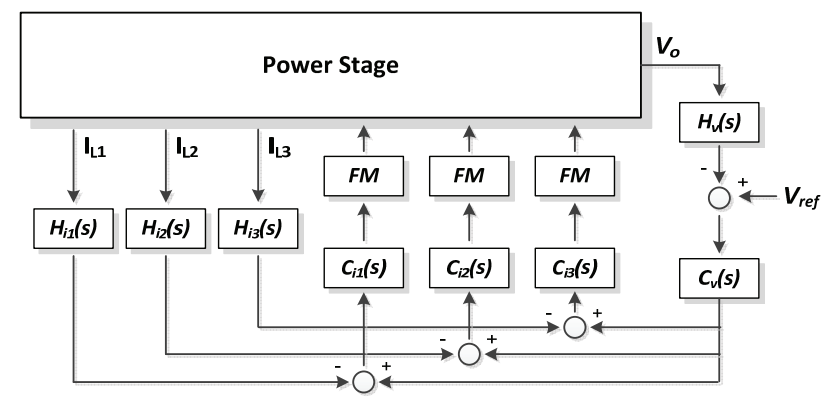

Fig. 7. System control block diagram. too high a switching frequency under light load condition. The PI controller is employed to cope with inductance variation and the switching frequency limitation condition. The PI controller for current and voltage compensation is designed to ensure stable operation at variable frequency control on the basis of the stability analysis.

Fig. 9 shows the open loop and compensated frequency response of the inner loop. The $\mathrm{R}(\mathrm{s})$ is regulator transfer function, $\mathrm{A}(\mathrm{s})$ is open loop transfer function, and $\mathrm{Cl}(\mathrm{s})$ is closed loop transfer function. The phase difference of the current controller for each phase is $120^{\circ}$, and the gain is the same. The bandwidth of the inner current loop is set at 2.37

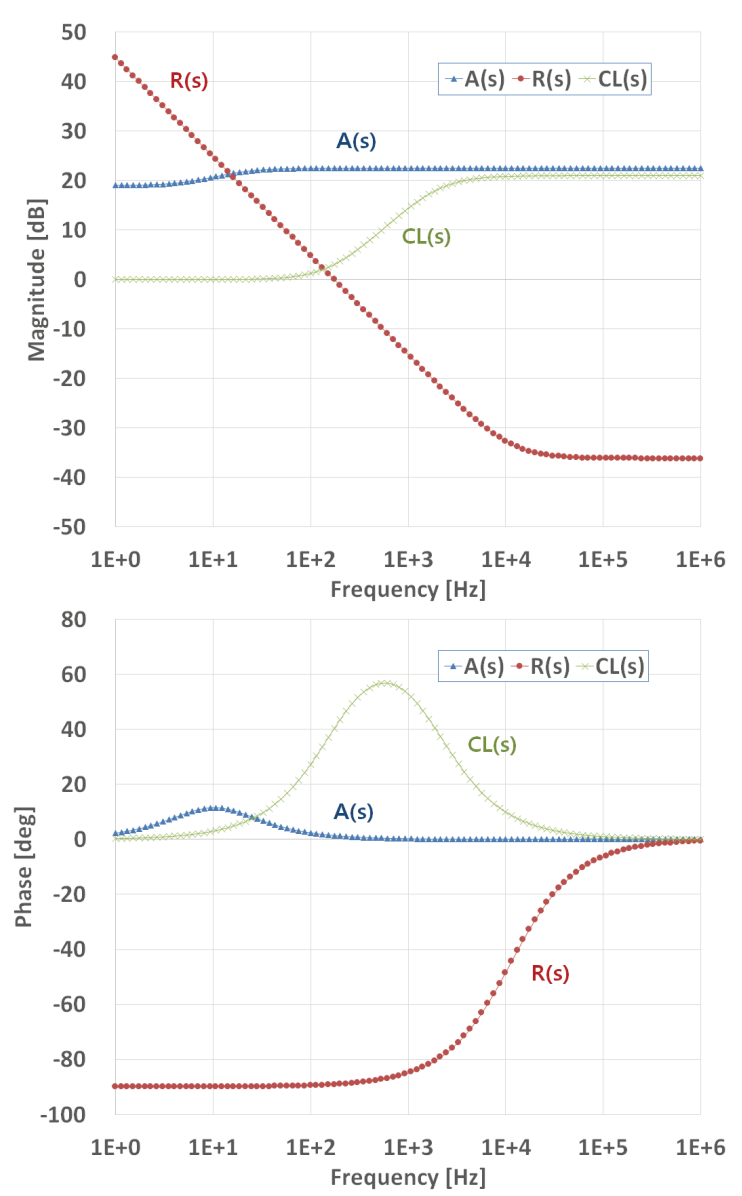

Fig. 9. Frequency response of compensated current

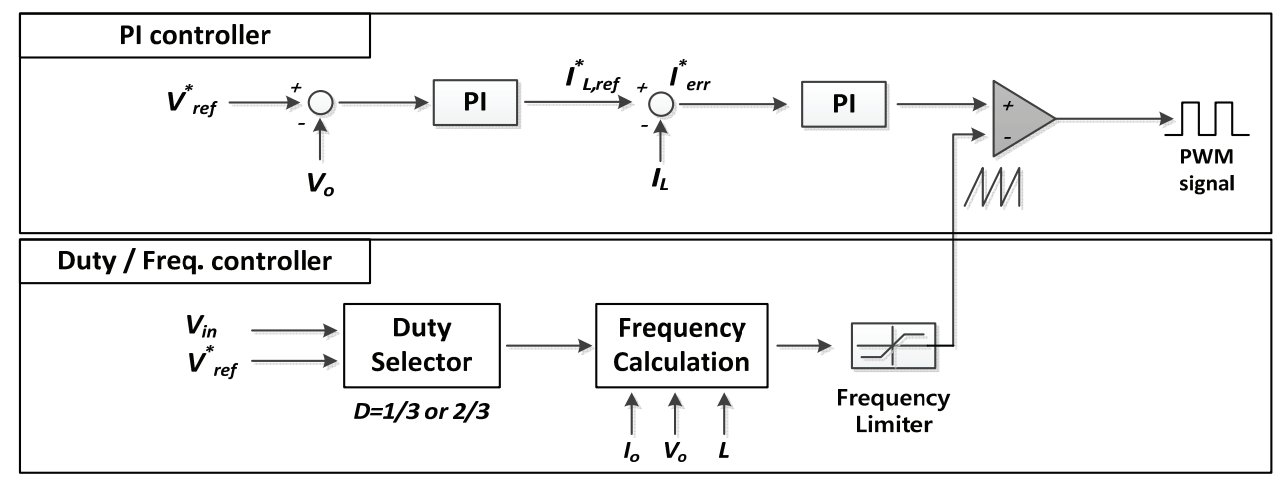

Fig. 8. Proposed frequency control DCM algorithm. 


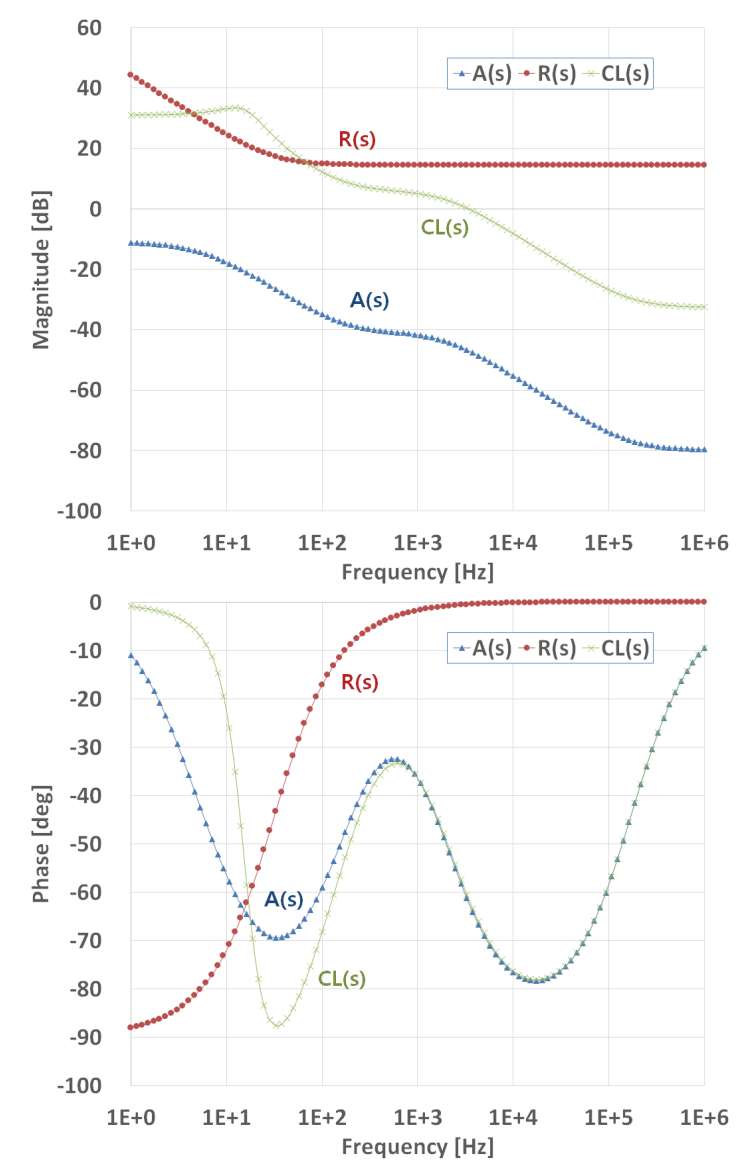

Fig. 10. Frequency response of compensated voltage

$\mathrm{kHz}$ considering the lowest switching frequency at $33 \mathrm{~V}$ input voltage. The PI controller is used as well for the outer voltage loop, as shown in Fig. 10. The bandwidth of the compensated outer voltage loop is $16 \mathrm{~Hz}$, and the phase margin is $53^{\circ}$. Both outer and inner loops are designed through PSIM Smartctrl in the frequency domain. The stability of the compensated loops over the entire operating frequency range is confirmed via the gain and phase margin.

\section{Verification of Proposed Algorithm}

In order to verify the proposed control algorithm, simulation and experiments have been performed with a $600 \mathrm{~W}$ prototype with the system parameters shown in Table 1.

Table 1. System specification

\begin{tabular}{c|c}
\hline Parameters & Value [Unit] \\
\hline Output power & $600[\mathrm{~W}]$ \\
\hline Input voltage & $33-60[\mathrm{~V}]$ \\
\hline Output voltage & $90[\mathrm{~V}]$ \\
\hline Output current & $6.67[\mathrm{~A}]$ \\
\hline Switching frequency & $11-37[\mathrm{kHz}]$ \\
\hline
\end{tabular}

\subsection{Inductor design}

For DCM operation, the inductance should be smaller than the boundary under the overall input voltage and switching frequency. The boundary inductance $L_{c r i t}$ is expressed as

$$
L_{c r i t}=\frac{V_{\text {in }} D(1-D)}{2 I_{o} f_{s w}} \times \frac{1}{f\left(I_{L}\right)}
$$

where $f\left(I_{L}\right)$ is the inductance correction term considering the permeability variation. The variation of the nominal inductance is

$$
A_{L}=f\left(N I_{L}\right) \times A_{L 0}
$$

After calculating the inductance value by the initial inductive factor $\mathrm{A}_{\mathrm{L} 0}$, the inductor current is estimated in the input voltage and the switching frequency in order to correct inductance decrease by the magnetizing force. Fig. 11 shows the boundary inductance value calculated by (11) for the switching frequency and the input voltage. Therefore,

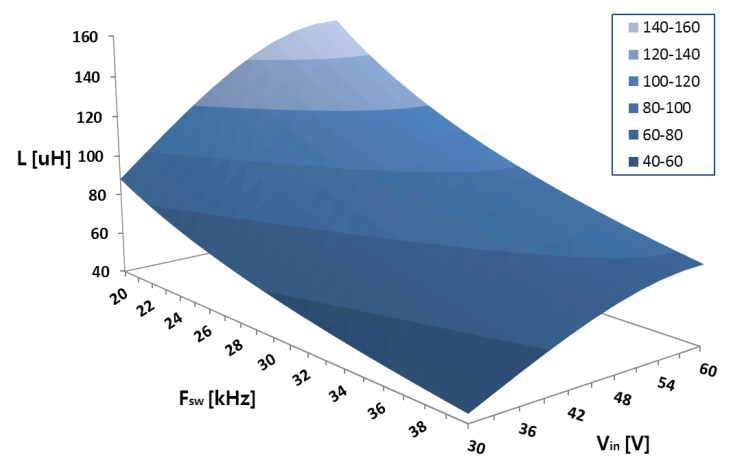

Fig. 11. Boundary inductance according to $F_{s w}$ and $V_{i n}$.

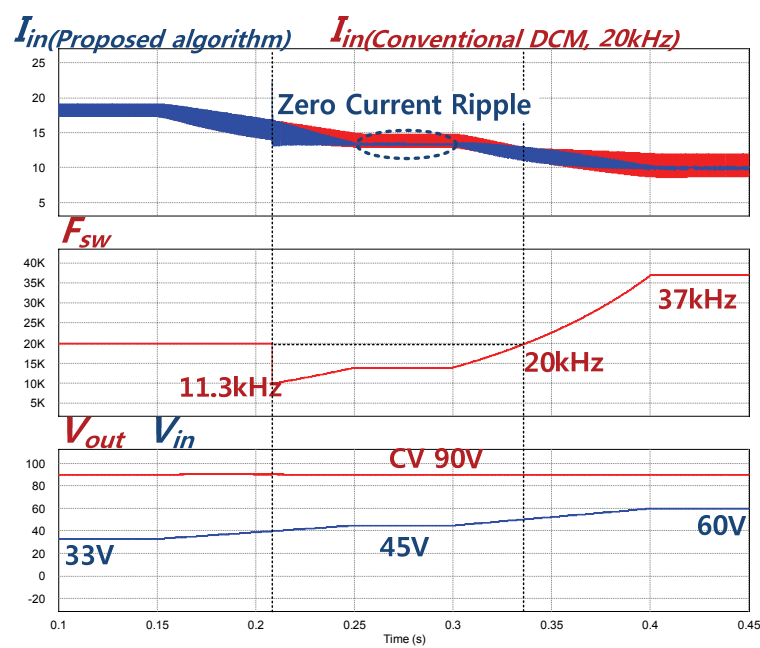

Fig. 12. Current ripple comparison of each algorithm. 
the inductance value should be designed under the lower part of the graph, and near the boundary condition $81 \mathrm{uH}$ is selected to reduce the current ripple.

\subsection{Simulation results of proposed algorithm}

The comparison of the input current ripple is shown in Fig. 12. If the calculated frequency is $11 \mathrm{kHz}$ or less, the input current ripple is higher than in the conventional DCM. Thus, a frequency limiter is employed to limit the input current ripple and prevent saturation of the inductor core.

In the case of an input voltage less than $50 \mathrm{~V}$, the calculated switching frequency from the proposed algorithm is lower than that from the conventional algorithm. In spite of the low switching frequency, the input current ripple is decreased owing to the ripple cancellation effect of the proposed control algorithm. The input current ripple is near zero at an input voltage of $45 \mathrm{~V}$ because of the symmetric $D$ and $D_{A}$ of each phase. This means the slope of each phase current is a constant value, represented in Fig. 13. Fig. 14 shows the comparison of the MOSFET switching loss and inductor loss of each control algorithm. The diode loss is assumed to be the same because it is determined by the average current. For both control algorithms, the inductor loss is decreased in accordance with the input voltage increase due to the reduction in the inductor current ripple and the rms value. On the other hand, in the proposed frequency control algorithm, the switching loss is

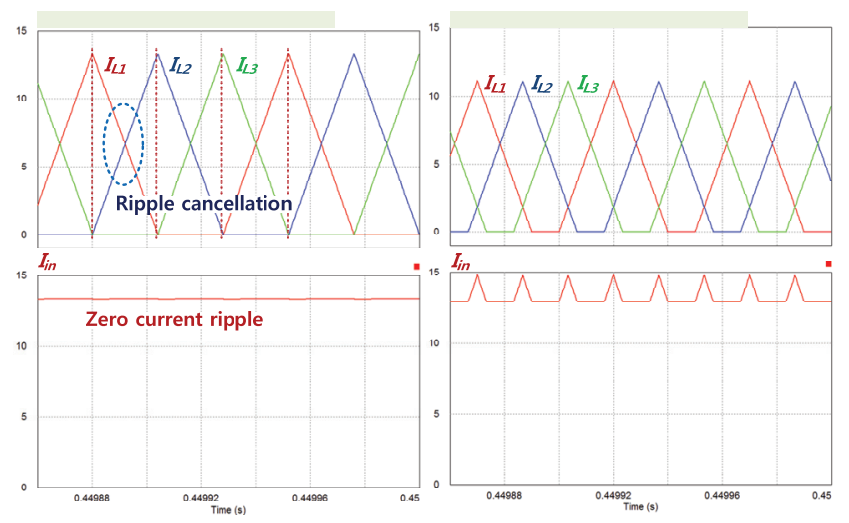

Fig. 13. Input current ripple comparison at $45 V_{\text {in }}$

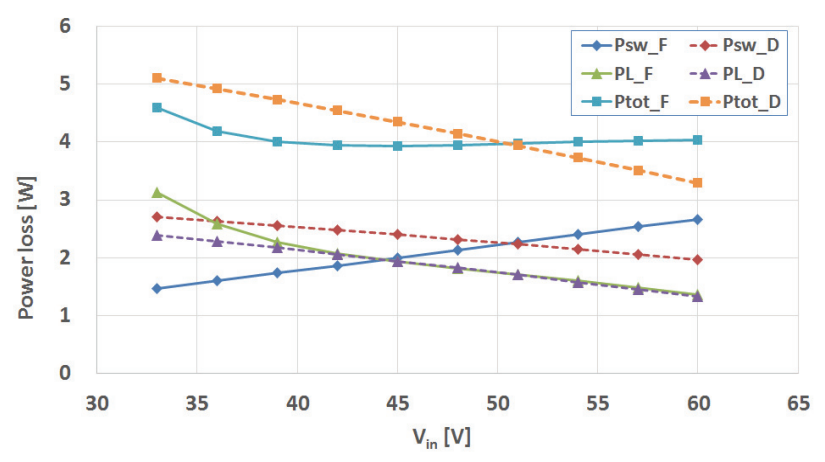

Fig. 14. Loss analysis of each algorithm at $600 \mathrm{~W}$ increased because of the rise in the switching frequency. Thus, the trend of the total loss is parabolic. Although the entire loss is higher above $50 \mathrm{~V}$ input voltage conditions, the difference in the losses of the algorithms is very slight in spite of the significant frequency difference.

\subsection{Experimental results of proposed algorithm}

In order to validate the proposed control algorithm, experimental tests were carried out by using $600 \mathrm{~W}$ hardware.

The special case of the proposed control algorithm is shown in Fig. 15. Although the switching frequency of the proposed algorithm is low, the input current ripple is near zero owing to the cancellation effect.

Fig. 16 shows the results of the simulation and experimental results of each algorithm according to the input voltage. The input current ripple of the proposed

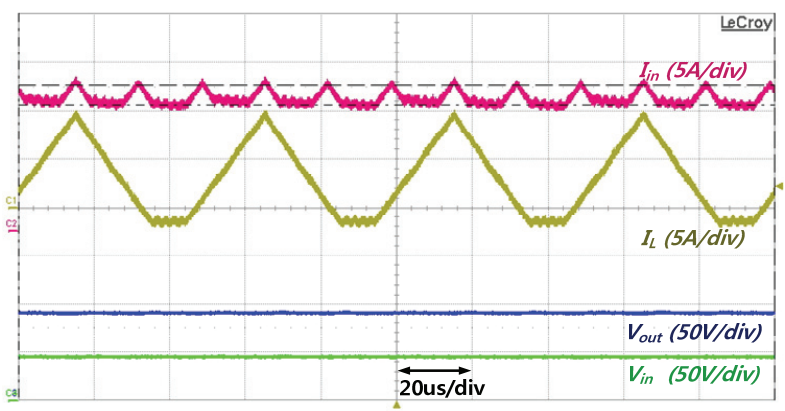

(a) Conventional duty control algorithm, $F_{s w}=20 \mathrm{kHz}$

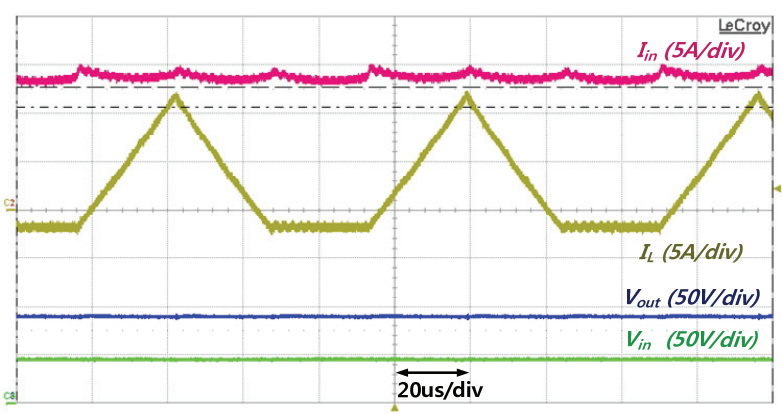

(b) Proposed frequency control algorithm, $F_{s w}=13 \mathrm{kHz}$

Fig. 15. Input current ripple of each algorithm at $600 \mathrm{~W}$.

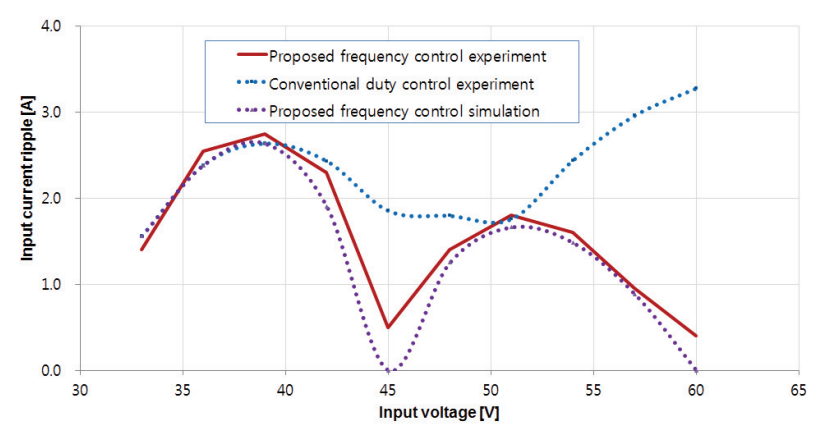

Fig. 16. Results of input current ripple according to $V_{i n}$. 


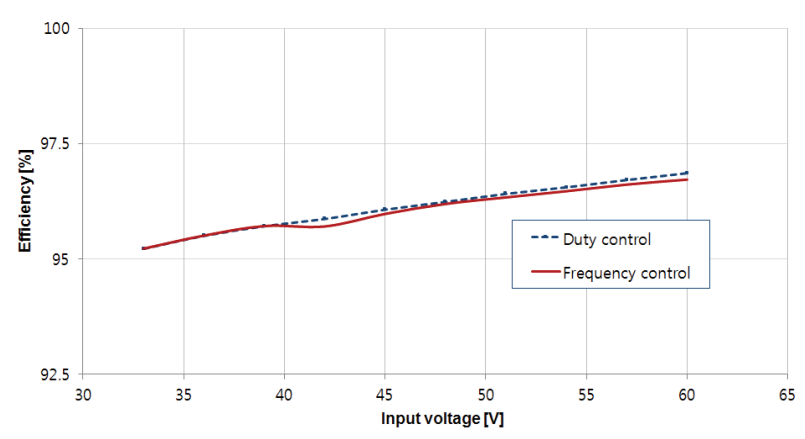

Fig. 17. System efficiency comparison of each algorithm.

algorithm is less or equal at specific input voltage range. With the proposed algorithm, an average input current reduction of $57 \%$ is obtained.

Fig. 17 shows the efficiency of each algorithm, and the difference is a little low because the proposed algorithm is based on the characteristics of DCM, and it can easily obtain the high-efficiency results of zero current turn-on. From the simulation and experimental results, it is noted that the proposed DCM frequency control algorithm is able to obtain reduction of input current ripple in addition to high efficiency.

\section{Conclusion}

This paper proposed a fixed duty and variable frequency control algorithm for the interleaved boost converter with the capability of input current ripple reduction. This is achieved without using additional components. In addition, the harmful effects of the diode reverse recovery current are eliminated by the DCM operation characteristic. The duty of the proposed algorithm is predetermined to minimize the input ripple current, and the output voltage is regulated by frequency control. The stability of the proposed algorithm is analyzed by Psim SmartCtrl 1.1

A $600 \mathrm{~W}$ three-phase boost converter prototype is designed to verify the proposed algorithm. An average ripple current is reduced $57 \%$ at $33 \mathrm{~V}-60 \mathrm{~V}$ input without an efficiency decrease. Moreover, the input current ripple is near zero at $45 \mathrm{~V}$ input in spite of the low switching frequency. These features can reduce the burden of power conversion system such as large input current and input filter.

\section{References}

[1] M. Rogol, S. Doi, and A. Wilkinson, "Sun screen: Investment opportunities in solar power," Solar Power Sector Outlook, CLSA Asia-Pacific Markets, Jul. 2004.

[2] D. H. Kim, G. Y. Choi, B. K. Lee, "DCM Analysis and Inductance Design Method of Interleaved Boost Converters", IEEE Trans Power Electron., vol. 28, no.
10, pp. 4700-4711, 2013.

[3] G. Y. Choe, J. S. Kim, H. S. Kang and B. K. Lee, “An Optimal Design Methodology of an Interleaved Boost Converter for Fuel Cell Applications", Journal of Electrical Engineering \& Technology, vol. 5, no. 2, pp. 319-328, Jun., 2010.

[4] N.K. Poon, J.C.P. Liu, C.K. Tse, and M.H. Pong, "Techniques for input ripple current cancellation: classification and implementation", IEEE Trans. Power Electron., vol. 15, no. 6, pp. 1144-1152, Nov. 2000.

[5] Birca-Galateanu, S., "Double DC-DC converters with low input current ripple", IEEE 31st Power Electronics Specialists Conference, vol. 2, pp. 837-842, Galway, 2000.

[6] Wang, J., Dunford, W.G., Mauch, K., "Analysis of a ripple-free input-current boost converter with discontinuous conduction characteristics", IEEE Trans. Power Electron., vol. 12, no. 4, pp.684-694, Nov. 1997.

[7] Leu, C. -S., Nha, Q. T, “A half-bridge converter with input current ripple reduction for DC distribution systems", IEEE Trans. Power Electron., vol. 28, no. 4, pp. 1756-1763, Apr. 2013.

[8] Rosas-Caro, J.C., Mancilla-David, F., Mayo-Maldonado, J.C., Gonzalez-Lopez, J.M., Torres-Espinosa, H.L., Valdez-Resendiz, J.E., “A transformer-less high-gain boost converter with input current ripple cancelation at a selectable duty cycle", IEEE Trans. Power Electron., vol. 60, no. 10, pp. 4492-4499, Nov. 2013.

[9] Heinz van der Broeck, Ibrahim Tezcan, "1 KW Dual Interleaved Boost Converter for Low Voltage Applications", Power Electronics and Motion Control Conference (IPEMC), Aug., 2006.

[10] Texas instruments, "Ringing reduction techniques for NexFET $^{\mathrm{TM}}$ high performance MOSFETs", TI Application Report, Nov. 2011.

[11] Wei Zhang, Xiucheng Huang, Fred C. Lee, Qiang Li, "Gate Drive Design Considerations for High Voltage Cascode GaN HEMT", IEEE Pro. APEC'2014, pp. 1484-1489, Mar. 2014.

[12] D. K. Kwak, "A Study on Isolated DCM Converter for High Efficiency and High Power Factor", Journal of Electrical Engineering \& Technology, vol. 5, no. 3, pp. 477-483, Sep., 2010.

[13] D. H. Kim, G. Y. Choe, and B. K. Lee, "Design and Control of an Optimized Battery Charger for an xEV based on Photovoltaic Power Systems," Journal of Electrical Engineering \& Technology, vol. 9, no. 5, pp. 1602-1613, Sep. 2014.

[14] Daniel W. Hart, "Introduction to power electronics", Prentice Hall, 1997.

[15] ChangSung Corporation, "Magnetic Powder Cores", Ver. 1.3, pp 43, 2013. 


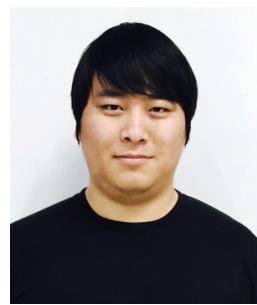

Dong-Myoung Joo $\mathrm{He}$ received the B.S. and the M.S. degrees from Sungkyunkwan University, Suwon, Korea, in 2011 and 2013, respectively. Since 2013, he has worked for his Ph.D. in Electrical Engineering at Sungkyunkwan University. His research interests include WBG semiconductor devices for dc-dc converters and inductive power transfer systems.

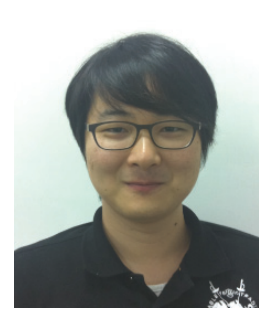

Dong-Hee Kim He received the B.S., the M.S., and the Ph.D. degrees from Sungkyunkwan University, Suwon, Korea, in 2009, 2011, and 2015 respectively. Since 2015, he has worked for his postdoctoral research associate at Sungkyunkwan University. His research interests include PCS and DC-DC converter for renewable energy and battery charger for $\mathrm{HEVs} / \mathrm{EV}$.

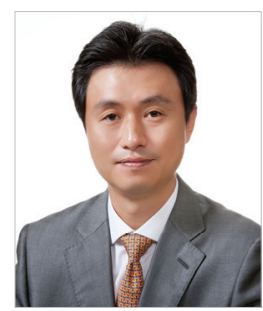

Byoung-Kuk Lee He received the B.S. and the M.S. degrees from Hanyang University, Seoul, Korea, in 1994 and 1996, respectively and the Ph.D. degree from Texas A\&M University, College Station, TX, in 2001, all in electrical engineering. From 2003 to 2005, he has been a Senior Researcher at Power Electronics Group, Korea Electrotechnology Research Institute (KERI), Changwon, Korea. From 2006 Dr. Lee joins at College of Information and Communication Engineering, Sungkyunkwan University, Suwon, Korea. His research interests include on-board charger and wireless power transfer for electric vehicles, energy storage systems, hybrid renewable energy systems, dc distribution systems for home appliances, power conditioning systems for fuel cells and photovoltaic, modeling and simulation, and power electronics. Prof. Lee is a recipient of Outstanding Scientists of the 21st Century from IBC and listed on 2008 Ed. of Who's Who in America and 2009 Ed. of Who's Who in the World. Prof. Lee is an Associate Editor in the IEEE Transactions on Industrial Electronics and Guest Associate Editor in the IEEE Transactions on Power Electronics. He was the Presenter for Professional Education Seminar with the topic of "On-Board Charger Technology for EVs and PHEVs" at IEEE Applied Power Electronics Conference in 2014 and was the General Chair for IEEE Vehicular Power and Propulsion Conference (VPPC) in 2012. 